\title{
Massive production of abiotic methane during subduction zone HP- UHP metamorphism in SW Tianshan, China
}

\author{
LIJUAN ZHANG ${ }^{1}$, XIAO WANG ${ }^{2}$, LIFEI ZHANG ${ }^{1}$, \\ RENBIAO TAO ${ }^{1} \&$ FENGXIA TIAN ${ }^{2}$
}

${ }^{1}$ The Key Laboratory of Orogenic Belt and Crustal Evolution, MOE; School of Earth and Space Sciences, Peking University Beijing 100871, China and e-mail address lijuanzhang@pku.edu.cn; lfzhang@pku.edu.cn

${ }^{2}$ School of Earth Sciences and Resources, China University of Geosciences, Beijing, China

Most natural gas reservoirs found in the world are biogenic genesis, whereas more and more methane $\left(\mathrm{CH}_{4}\right)$ was found to be abiotic. Abiotic methanogenesis at shallow conditions is well documented, whereas the $P-T-f \mathrm{O}_{2}$ conditions and formation genesis at greater depths are still poorly understood. $\mathrm{CH}_{4}$ could move upward via mantle wedge, return to the surface by degassing at arc volcanoes and further influence the gas accumulation, climate and environment. Here we first identify massive abiotic $\mathrm{CH}_{4}$-bearing fluid inclusions (FIs) in garnet and omphacite, in ultrahighpressure (UHP) eclogites from the Western Tianshan cold subduction zone in China. We assess the geochemistry of $\mathrm{CH}_{4}$-bearing FIs and find that they contain $\mathrm{CH}_{4}$ and variable minor $\mathrm{N}_{2}$ in vapor, $\mathrm{H}_{2} \mathrm{O}$ in fluid phase, with/without solid phase of calcite, graphite, rutile and quartz. Petrological study and phase equilibrium modeling indicate that the massive $\mathrm{CH}_{4}$ could be produced in HP-UHP conditions during subduction. The $\mathrm{CH}_{4}$-bearing FIs in garnet record that they occurred from the prograde metamorphic stage at P-T conditions of $21-23 \mathrm{kbar}, 520-530^{\circ} \mathrm{C}$ and oxygen fugacity condition of FMQ - $2.4 \log$ units, to UHP peak condition of 32-34 kbar, $540-560^{\circ} \mathrm{C}$ and FMQ - $3.4 \log$ units. Thus, we documented the first natural case of massive reduced carbon $\left(\mathrm{CH}_{4}\right)$ liberation by deep subduction fluids at $P-T$ conditions of sub-arc depth. The UHP eclogites may represent an important source of abiotic $\mathrm{CH}_{4}$, with significant implications for deep carbon cycle and gas accumalation. Cold subduction zone is a most important factory for abiotic $\mathrm{CH}_{4}$. 